\title{
How to handle borderline/precursor thyroid tumors in management of patients with thyroid nodules
}

\author{
Kennichi Kakudo \\ Department of Pathology, Kindai University Faculty of Medicine, Nara Hospital, Nara, Japan \\ Correspondence to: Kennichi Kakudo, MD, PhD. 1248-1 Otoda-cho, Ikoma City, Nara 630-0293, Japan. Email: kakudo@thyroid.jp.
}

\begin{abstract}
Thyroid carcinomas originating from follicular cells have the prognosis of heterogeneous diseases, but pathologists classify them all as malignant disease. Epidemiologists have issued a stern warning regarding over-diagnosis and overtreatment of patients with indolent thyroid tumors that cause no harm to the patients. Review of the literature revealed that there were several proposals of borderline/precursor tumors to some indolent thyroid carcinomas. Thyroid tumor of uncertain malignant potential (UMP) was first proposed by Williams for encapsulated follicular pattern thyroid tumors to solve problems due to observer variation. Rosai et al. proposed to rename papillary microcarcinoma (PMC) to papillary microtumor as the overwhelming majority of them are of no clinical significance. Liu et al. proposed welldifferentiated tumor with uncertain behavior (WDT-UB) which covered WDT of UMP (WDT-UMP) and non-invasive encapsulated follicular variant of papillary thyroid carcinoma (EFVPTC). The EFVPTC without invasion was renamed as non-invasive follicular thyroid neoplasm with papillary-like nuclear features (NIFTP) by an international panel of pathologists. A new prognostic classification of thyroid tumors was proposed by Kakudo et al., in which extremely low risk tumors were grouped in a borderline tumors category. The borderline/precursor thyroid tumors included encapsulated tumors [capsular invasion only follicular carcinoma, encapsulated papillary carcinoma without invasion, WDT-UMP and follicular tumor of UMP (FT-UMP)] and non-encapsulated tumors (PMC). The UMP and NIFTP were incorporated in the 4th edition WHO classification of thyroid tumors as a new tumor entity in chapter 2-2A: other encapsulated follicular patterned thyroid tumors. Their behavior codes were decided to be 1 (borderline or uncertain behavior), and not 0 (benign), 2 (in situ carcinoma) or 3 (malignant). These borderline/precursor thyroid tumors are indolent tumors biologically and should be treated more conservatively than as previously recommended for thyroid follicular cell carcinomas [total thyroidectomy (TTX) followed by radio-active iodine (RAI) treatment] by western clinical guidelines.
\end{abstract}

Keywords: Borderline tumor; non-invasive follicular thyroid neoplasm with papillary-like nuclear features (NIFTP); microcarcinoma; precursor tumor; thyroid; uncertain malignant potential (UMP)

Submitted Jun 18, 2017. Accepted for publication Jul 26, 2017.

doi: 10.21037 /gs.2017.08.02

View this article at: http://dx.doi.org/10.21037/gs.2017.08.02

\section{Proposal of borderline/precursor thyroid tumors}

In 2009, our group proposed a new classification of thyroid tumors, which was characterized by a borderline tumor category (1), and it was updated in 2011, 2012 and 2015 (Table 1) (2-6). Surprisingly, no borderline/precursor lesions of follicular cell tumor lineage were defined in the previous 3rd edition of the WHO classification of thyroid tumors (7), whereas in $\mathrm{C}$ cell tumor lineage, $\mathrm{C}$ cell hyperplasia (C cell carcinoma in situ) was defined as a precursor or early stage of $\mathrm{C}$ cell carcinoma (8-11). The borderline/precursor tumors in the thyroid follicular cell tumor classification proposed by Kakudo included encapsulated tumors [capsular invasion only follicular carcinoma, encapsulated papillary carcinoma without invasion, well-differentiated tumor of uncertain malignant potential (WDT-UMP) and follicular tumor of UMP (FT-UMP)] and non-encapsulated tumors [papillary microcarcinoma (PMC)] (Table 1) $(3,6)$. 
Table 1 The borderline tumor category in prognostic classification of follicular cell tumors using Ki-67 labeling index proposed by Kakudo (1-6)

Benign tumors (Ki-67 LI: <3\%)
Follicular adenoma
Borderline (precursor) tumors (Ki-67 LI: <3\%, and T1, NO, EXO
and M0)
Encapsulated tumors
Capsular invasion only follicular carcinoma
Encapsulated papillary carcinoma without invasion
Well-differentiated tumor of uncertain malignant potential
Follicular tumor of uncertain malignant potential
Non-encapsulated tumors (formerly called papillary
microcarcinoma)
Papillary micro-tumor (<1 cm)
Malignant tumors (invasive carcinoma and $>1 \mathrm{~cm}$ )
Low risk (Ki-67 LI: <5\%)
Moderate risk (Ki-67 LI: 5-10\%)
High risk (Ki-67 LI: 10-30\%)
Undifferentiated carcinoma (Ki-67 LI: $>30 \%$ )

\section{Indolent thyroid tumors}

Encapsulation and well-circumscribed or expansive growth were reported to be significant indicators of favorable prognosis of thyroid carcinomas by many authors (12-16). Piana et al. analyzed their 1,009 consecutive cases with thyroid carcinoma treated at a single Italian hospital with average 11.9 years follow-up (15). They found no cancer death in their 66 cases of encapsulated follicular variant PTCs (45 cases without invasion and 21 cases with invasion), 29 cases of minimally invasive follicular carcinomas (23 cases with capsular invasion only and 3 cases with vascular invasion), 6 cases of well differentiated carcinoma, not otherwise specified, 5 cases of WDT-UMP and 6 cases of FT-UMP (15). Memorial Sloan Kettering Cancer Center group reported that their non-invasive encapsulated follicular variant PTCs treated with surgery alone did not developed recurrence or metastasis (17-19) and it was confirmed by Nikiforov et al. with their large $(\mathrm{n}=109)$ patient series (20). In non-encapsulated tumors, PMC of the thyroid has been reported as a common finding, $11.5 \%$ on autopsy and $25-30 \%$ on ultrasound examination (21). It was concluded that PMC was a normal finding in adult autopsy thyroid glands in Finland by Harach et al. because it was found in more than $35 \%$ of autopsy patients and did not cause any symptoms or direct cause of patient's death (22).

\section{Active surveillance to the patient with PMC}

An observation trials of patients with clinical PMC was initiated by Miyauchi et al. in 1993 (23) and conducted by two independent groups of surgeons in Japan (24-29). Observations in these patient cohorts proved that more than $86 \%$ of PMCs were stable (no change), decreased in size or disappeared during an average 5-year followup (30). The remaining 14\% of patients accepted surgery after a certain period of clinical follow-up. Those patients accepted surgery after lymph node metastasis or tumor enlargement were detected, or when patients changed their mind and dropped out from the observation program (24-29). It was clearly demonstrated that the vast majority of intrathyroidal (low risk) PMCs were very slow growing carcinoma (cancer that never causes problems because the patient will die of some other cause before the cancer is large enough to produce symptoms) defined by Welch and Black (31), or an IDLE (indolent lesion of epithelial origin, which are currently labelled as cancers and their precursors that are unlikely to cause harm if they are left untreated) proposed by Esserman et al. (32). All patients who dropped out from this program were treated with so-called rescue (delayed) surgery successfully without increased mortality and morbidity, and no persistent disease or cancer death was reported in those patients during more than 5 years of follow-up (23-29). In Kuma hospital patient series ( $n=1,235)$, $8 \%$ of patients showed tumor enlargement by $3 \mathrm{~mm}$ or more at 10 years of observation, and $3.8 \%$ of patients showed novel appearance of lymph node metastasis at 10 years (23).

Assignment to observation and immediate surgery groups was not random but based on the patient's choice after thorough consultation. Please note that the follow-up (observation without surgery) group of patients with PMC in these studies was not a control group with no treatment because these patients could select surgical treatment at any time freely (23). The aim of this active surveillance program of patients with $\mathrm{PMC}$ is to avoid unnecessary immediate surgery, which may create significant risk of overtreatment and treatment-related complications, while at the same time identify patients with a potentially higher risk for progression, such as growing thyroid nodules, 
blurred tumor margins or new lymph node enlargements by ultrasound image. These authors concluded that immediate surgery for PMC is not necessary, and observation with full follow-up (so-called active surveillance) is one choice for those patients. Miyauchi concluded, although he still offers two options, immediate surgery or observation, to patients with low-risk PMC at Kuma hospital, that he now strongly recommends observation as the best choice (23). Under this clinical practice at Kuma Hospital, PMCs occupied only about $10 \%$ of surgically treated primary thyroid carcinomas (personal communication).

\section{Treatments of PMC in western practice}

While in the past US practice, $73.4 \%$ of 29512 patients with PMC were treated with total thyroidectomy (TTX) and $31.3 \%$ of patients were treated with radio-active iodine (RAI) from an analysis of the Surveillance, Epidemiology and End Results database by Wang et al. (33). Permanent hypothyroidism is unavoidable in all patients who receive TTX and a significant proportion of patients who are treated with lobectomy later develop hypothyroidism, as a result, and life-long thyroid hormone administration is necessary for these patients. Surgical complications (hematoma, infection, hypoparathyroidism or laryngeal nerve dysfunction) were reported in $15.1 \%$ of 1,379 patients treated with thyroidectomy $(5.6 \%$ in lobectomy and $18.0 \%$ in TTX) for follicular neoplasm (FN) nodules in 26 Italian hospitals (34) and Leboulleux et al. concluded that permanent complications from surgery cannot be decreased to less than 1-3\% even in high-volume tertiary care centers with experienced surgeons (21). Incidence of second primary malignancy in patients with thyroid cancer treated with RAI was reported to be high in salivary gland malignancies and leukemia (35). Lang et al. found that nonsynchronous second primary malignancies accounted for $18.7 \%$ of all death in differentiated thyroid cancers, and mortality of second primary malignancies was very high (43.5\%) (36). Thyroidnews <thyroidnews@news.thyroid. org $>$, released from the American Thyroid Association (ATA) on $18^{\text {th }}$ of August, 2016, stated that (I) do not perform thyroid fine needle aspiration (FNA) on nodules less than $1 \mathrm{~cm}$ unless there is evidence of extrathyroidal extension or of lymph node or distant metastases; and (II) restrict surgery to lobectomy and avoid RAI to those with low risk features. The cancer diagnosis by pathologists for thyroid nodules, less than $1 \mathrm{~cm}$, is not accepted or almost denied by the ATA management guidelines officially. This was a strategy by the ATA to reduce overtreatment of indolent thyroid tumors (37), although expert pathologists already proposed to rename PMC to papillary micro-tumor in 2003 (38) and Kakudo et al. classified it in the borderline tumor category $(3,6)$. These proposals for borderline/ precursor tumors in the thyroid tumor classification were attempts by pathologists to stop over-diagnosis of indolent tumors. In a same time, the concept of active surveillance for patients with PMC proposed by a Japanese surgeon (23) was endorsed by the ATA thyroid cancer management guidelines as an alternative to immediate surgery and is adopted by the leading thyroid clinics in Korea, USA and EU countries (21,39-41). Although Nickel et al. suggested that clinicians may not be ready to accept nonsurgical options or change in terminology until evidence to support these options and changes is stronger (42).

\section{Proposal of NIFTP and the new $4^{\text {th }}$ edition of the World Health Organization classification of endocrine organs}

Several authors reported the controversial nature of the follicular variant of papillary thyroid carcinoma (FVPTC). It is a heterogeneous group of tumors, including noninvasive encapsulated FVPTC, invasive encapsulated FVPTC and invasive non-encapsulated (infiltrative) FVPTC, which are different biologically and have different genetic alterations (17-19,43-45). However, patients with these were treated equally as for thyroid carcinoma with TTX and RAI in western practice $(46,47)$. This was due to the $3^{\text {rd }}$ edition WHO classification of thyroid tumors. There is a follicular variant in the chapter for PTC. It states that approximately one third of the tumors are encapsulated. Although complete encapsulation, lymph node and rare hematogenous metastasis can occur, the prognosis of these tumors is similar to that of usual papillary carcinoma (7). With this incorrect description, it was estimated that more than 45,000 patients with the non-invasive encapsulated FVPTC (EFVPTC) were treated with TTX and RAI annually worldwide (20).

Revision of this statement was an urgent issue for the WHO editorial committee. In 2015, an international working group for re-examination of the EFVPTC was conducted by Professor Yuri Nikiforov at the University of Pittsburgh. After examination of 210 cases (109 cases without invasion and 101 cases with capsular and/or vascular invasion), the working group concluded that non-invasive EFVPTC was a neoplasm of very low 
malignant potential. No further surgery after complete excision or RAI therapy is required for majority of these tumors based on prior studies of non-invasive EFVPTCs. This working group proposed a new terminology, "non-invasive follicular thyroid neoplasm with papillary-like nuclear features" (NIFTP), for this lesion to replace the cancer terminology (20). The working group further postulated it as an oncogene driven clonal tumor and a precursor tumor to invasive EFVPTC. Following this publication, the WHO editorial committee decided to incorporate a new chapter, 2-2A: other encapsulated follicular patterned thyroid tumors, in which there were two sub-chapters, UMP and NIFTP, in the $4^{\text {th }}$ edition WHO classification of tumors of endocrine organs (48). They were given a behavior code of 1 (borderline or uncertain behavior) by the WHO committee (48).

\section{Incidence of NIFTP and diagnostic criteria of borderline/precursor tumors}

It is well-known that there is significant observer variation in evaluation of PTC-type nuclear features in encapsulated follicular pattern thyroid tumors between eastern and western pathologists (49-51). This may be caused by a protective diagnostic attitude in western practice postulated by several authors (52-55) and a stricter diagnostic criterion of PTC was recommended by some authors $(1-4,49,50,56,57)$. Therefore, the diagnostic frequency of NIFTP (non-invasive EFVPTC) was different among practices due to varying diagnostic thresholds for PTC-N. From western practice, rates of NIFTP were usually high and Strickland et al. and Thompson from the USA reported their incidences of NIFTP as high as $25 \%$ of malignancies, Faquin et al. reported $23 \%$ of PTCs from their analyses of five American and Italian academic centers (58-60), Pusztaszeri et al. from Switzerland reported their rate of NIFTP was $13.8 \%$ (61) and few authors reported less than $10 \%(15,62)$. From Asian practice, Bychkov et al. summarized 9 institutions from 6 Eastern and Southeastern Asian countries and reported very low rates, average $0.8 \%$ (range, $0-4.7 \%$ ) of NIFTP (63). This observation is in the line from other Asian studies where NIFTP accounted for $0.4 \%$ in Japan (2), $0.4 \%$ in China (64) and $0.3-3.4 \%$ in Korea (65), whereas some authors reported a very high rate, $27 \%$ by Canberk et al. from Turkey (66).

\section{NIFTP and UMP}

To solve observer variation in diagnosis of EFVPTC, Williams proposed WDT-UMP and defined it as an encapsulated tumor composed of well-differentiated follicular cells with well or partially developed PTC-type nuclear changes, and exhibiting questionable capsular or vascular invasion (67). These NIFTP and WDT-UMP had significant overlap in original proposals as shown in Table 2, and the $4^{\text {th }}$ edition WHO classification tried to separate them and modified the diagnostic criteria slightly as shown in Table 3 (48). However, our group proposed to classify both WDT-UMP and NIFTP (NIFTP was an encapsulated non-invasive FVPTC in 2011) into one borderline tumor category and named it WDT with uncertain behavior (WDT-UB) in 2011 (Table 4) (2). This strategy may be easier and possibly minimizing observer variation in diagnosis of borderline tumors, if they have negligible differences for clinical purposes, such as in clinical management workflow. However, in this review, the author would like to recommend readers to diagnose these lesions separately because we are not sure yet that they are actually in the same disease entity of borderline/precursor tumor that can be treated similarly. We need further studies to clarify any progression risk of each borderline/precursor thyroid tumors and confirm active surveillance of these tumors does not create any increased-risk of mortality of the patient. I believe it is possible to confirm or deny those questions, simply because differences between Western and Asian practices provide a good experimental design, as the western practice serves a surgery group to borderline/ precursor tumors and Asian practice serves a non-surgical control group (active surveillance until progression appear).

\section{Are they surgical diseases?}

Is NIFTP a surgical disease? Many authorities in western practice concluded that NIFTP is a surgical disease (68) because only thorough examinations of the entire tumor capsule can establish the non-invasive nature of the tumor. It was emphasized by many authors under western logic and way of thinking that the first priority was given to avoiding missing malignancy rather than minimizing invasive tests. In Asian society, a Chinese philosophy, Xiao Jing (the body, hair and skin, and all have been received from the parents, thus one does not dare damage them-this is the beginning of Xiao) has deep impacts on clinical practice, which is almost an equivalent principle to "primum non nocere" (first, do not harm 
Table 2 Recommended nomenclatures for encapsulated well differentiated follicular-pattern thyroid tumors on the basis of the presence or absence of papillary thyroid carcinoma (PTC) type nuclear features and capsular/vascular invasion proposed by Williams ED in 2000 (67)

\begin{tabular}{llll}
\hline \multirow{2}{*}{ PTC type nuclear features } & \multicolumn{1}{c}{ Capsular/vascular invasion } \\
\cline { 2 - 4 } & Present & Questionable/incomplete & Absent \\
\hline Questionable/incomplete & $\begin{array}{l}\text { Well-differentiated } \\
\text { carcinoma, NOS }\end{array}$ & Follicular variant PTC & Well-differentiated tumor of uncertain malignant potential (WDT-UMP) \\
Absent & Follicular carcinoma & Follicular tumor of uncertain malignant & Follicular adenoma \\
& & potential (FT-UMP) & \\
\hline
\end{tabular}

NOS, not otherwise specified.

Table 3 A new definition of follicular variant PTC, NIFTP (non-invasive follicular thyroid neoplasm with papillary-like nuclear features) and WDT-UMP in the $4^{\text {th }}$ edition WHO classification (48)

\begin{tabular}{llll}
\hline \multirow{2}{*}{ PTC type nuclear features } & \multicolumn{2}{c}{ Capsular/vascular invasion } \\
\cline { 2 - 4 } & Present & Questionable/incomplete & Absent \\
\hline Present & Follicular variant PTC & $\begin{array}{l}\text { Well-differentiated tumor of } \\
\text { uncertain malignant potential (WDT- }\end{array}$ & $\begin{array}{l}\text { Non-invasive follicular thyroid } \\
\text { neoplasm with papillary-like } \\
\text { nuclear features (NIFTP) }\end{array}$ \\
Absent & $\begin{array}{l}\text { Well-differentiated } \\
\text { carcinoma, NOS }\end{array}$ & UMP) & Follicular adenoma \\
& Follicular carcinoma & $\begin{array}{l}\text { Follicular tumor of uncertain } \\
\text { malignant potential (FT-UMP) }\end{array}$ & \\
\hline
\end{tabular}

NIFTP comprises non-invasive part of follicular variant PTC and WDT-UMP.

Table 4 Well-differentiated tumor with uncertain behavior proposed by Liu et al. covers both NIFTP and WDT-UMP (2)

\begin{tabular}{llll}
\hline \multirow{2}{*}{ PTC type nuclear features } & \multicolumn{2}{c}{ Capsular/vascular invasion } \\
\cline { 2 - 4 } & Present & Questionable/incomplete & Absent \\
\hline Present & Follicular variant PTC & Well-differentiated tumour with uncertain behavior (WDT - UB) = \\
Questionable/incomplete & Well-differentiated carcinoma, & WDT - UMP + NIFTP & Follicular adenoma \\
Absent & NOS & Follicular tumor of uncertain \\
& Follicular carcinoma & malignant potential & \\
\hline
\end{tabular}

Observer variation between NIFTP and WDT-UMP is not a problem in this schema and both are borderline/precursor tumors and biologically benign after excision.

patients) in the Hippocratic Oath of western society $(69,70)$. Many endocrinologists and endocrine surgeons in Japan often feel guilty and are ashamed of their improper risk stratification if the nodule turns out to be a benign nodule after surgery (71). Diagnostic surgery is harmful and should be minimized to the patient, even if the surgery is restricted to a lobectomy. Significant numbers of patients later develop hypothyroidism and a few exhibit hypoparathyroidism and/or laryngeal nerve dysfunction $(21,23,29,30,34,41,72,73)$. A surgical wound or scar on the patient's neck is $100 \%$ unavoidable, which violates Xiao Jing, and surgery is acceptable in Asia only when the disease is intolerable or life threatening (70).

\section{Preoperative diagnosis of borderline/precursor tumors}

Some authors reported preoperative diagnosis of NIFTP are possible or at least can be suggested on cytological 
examination (61,74-84). Most NIFTPs display only poorly developed PTC type nuclear features including nuclear enlargement and delicate nuclear grooves, but nuclear cytoplasmic inclusions were not found in majority of cases. They were often classified in the indeterminate (AUS/FLUS, FN/SFN or suspicious for malignancy) cytological categories (61,74-84). The author of this review has proposed to rename indeterminate category to dysplastic category to accept borderline/precursor tumors (70). A thyroid nodule in FN/SFN cytological category is usually not life threatening at more than $99 \%$ probability $(85,86)$ and many of them belong to borderline/ precursor tumors $(58,60,70,75,77,87)$. Liu et al. concluded that Bethesda reporting system and cytological diagnosis imparts important prognostic information about cancer type, variant, and risk of recurrence because they were few in the FN/SFN nodules (88). However, in western practice, high resection rates $(60-80 \%)$ and very low risks of malignancy (ROMs) (10-30\%) were reported in the FN/ SFN cytological category, simply because diagnostic surgery on the patient with a FN/SFN nodule was recommended by the Bethesda reporting system and it was often accepted by the patient $(45,46,89-91)$.

\section{Risk stratification of patients with indeterminate nodule and active surveillance of patients with borderline/precursor tumors}

This author would like to emphasize that proper risk stratification of indeterminate thyroid nodules is paramount for reducing overtreatment, and this strategy in Japan made ROMs of indeterminate nodules (both AUS/FLUS and FN/ SFN) very high in general (more than 50\%) and resection rates low (less than 50\%) (70,90-92). As a personal view, this author has a different answer to the question, "Is NIFTP a surgical disease?" Based on our experience with FN/ SFN nodules, "No, borderline/precursor thyroid tumors including NIFTP are not surgical diseases". As majority of borderline/precursor tumors including NIFTP and WDTUMP are classified into so-called indeterminate cytological categories $(58,60-62,66,75,78,81,87)$, thyroid ultrasound helps triage higher risk patients to surgery and patients with benign finding can be followed (93-98). Nakamura et al. compared two groups of FN/SFN nodules that underwent active surveillance or immediate surgery. They demonstrated that growing nodules had a higher ROM on histology than that in the immediate surgery group (93). As the majority of cases with indeterminate nodules are borderline/precursor tumors and can be followed without invasive tests as long as they have benign clinical features recommended by the JTA clinical guidelines $(71,92,93,99,100)$, the author advises endocrinologists and endocrine surgeons in western practice to recommend surgery to patients with FN/SFN nodules provided that they have clinical high-risk features, and a careful followup is enough for patients with benign clinical features. It is also emphasized from western practice that proper triage of patients with FN/SFN nodule is of paramount importance to decrease unnecessary surgeries $(101,102)$. In 2015 ATA management guidelines, this strategy was partly incorporated in recommendation 16 to apply risk stratification of patients with FN/SFN nodules (37). It states that diagnostic surgical excision is the long-established standard of care for the management of FN/SFN cytology nodules in western practice. However, after consideration of clinical and sonographic features, molecular testing may be used to supplement malignancy risk assessment data in lieu of proceeding directly with surgery (37). It means molecular tests may help triage patients with indeterminate nodules in this risk stratification, but not yet available widely in the world outside USA and their positive and negative predictive values are not high enough. The ATA guidelines further commented that it is important to note that long term outcome data on companion use of molecular marker status to guide therapeutic decision-making is currently lacking (37). It is beyond the scope of this review to go into the molecular tests and their detailed usefulness and limitations. Please refer to the other publications in this focused issue.

\section{Treat, not-treat, or close follow-up}

Please consider that Welch and Black estimated an overdiagnosis probability of $99.7 \%$ to $99.9 \%$ when an entire thyroid cancer reservoir is detected (31). The above estimate does not mean that diagnostic surgery is not justified for patients with indeterminate thyroid nodules. From shared decision-making processes, some patients with indeterminate nodules may wish to remove them and to be free from the psychological burden of having a possible cancer, even if it is rare. For this purpose, clinicians must be fully aware of the demerits of diagnostic surgery and probability of treatment-related complications, as well as the ROM of the patient (103). Furthermore, careful followup of patients with indeterminate nodules is one choice of treatment options in clinical guidelines of Japan and 
this risk stratification of the patient using clinical tests minimizes missing malignancy and unnecessary diagnostic surgery $(71,92,93,104-106)$. This conclusion was supported by Wienhold et al. who emphasized that improper risk stratification of patients increased the number of surgeries for diagnostic purposes and very low ROMs at histology, as low as less than $7 \%$, almost equal to the background risk of malignancy, elucidated from their analysis of billing data to a health insurance company in Germany (107).

\section{Conclusions}

It is essential to establish more accurate histological criteria to identify true cancers that may recur or metastasize and result in cancer death in significant proportion of the patients if left untreated. It is also essential to exclude benign follicular adenoma and indolent borderline/precursor tumors from lethal cancers because they can be treated with simple excision. Unfortunately, borderline/precursor tumors were often treated equally and as radically as lethal malignant thyroid tumors in western clinical practices. Although in Asian practice the borderline/precursor tumors were neglected and were handled as if they were completely benign tumors. I believe we need a bridge between the practices to fill the gaps. I hope the introduction of the borderline tumor category in thyroid tumor classification will open a new era where pathologists have 3 choices for their diagnoses: benign, borderline, or malignant. Pathologists are no longer forced to decide between benign and malignantit can be a borderline or precursor tumor. I believe this causes significant changes not only in pathology practice, but also brings significant impacts to clinical management of patients. It opens a new era for endocrinologists and endocrine surgeons to have three treatment options for patients with thyroid nodules, treat, not treat, or close follow-up (active surveillance), which would be different from the current clinical management with two choices (treat or not treat). This has already been employed in clinical management of patients with low-risk PMC and FN/SFN nodule in Japan, and active surveillance (observation without immediate surgery) has become one of the treatment options. It was incorporated to some extent in the 2015 ATA clinical guidelines. This author predicts it may be incorporated into clinical management of all thyroid borderline/precursor tumors in the future to reduce over-diagnosis and overtreatment of patients with indolent thyroid nodules.

\section{Acknowledgements}

I would like to express my deep appreciation to all members of the Working Group of Asian thyroid FNA cytology and to my life-time clinical colleagues who are members of Kuma Hospital, Nara Hospital and Yamashita Thyroid Hospital for their helpful advices and discussion.

\section{Footnote}

Conflicts of Interest: The author has no conflicts of interest to declare.

\section{References}

1. Kakudo K, Bai Y, Katayama S, et al. Classification of follicular cell tumors of the thyroid gland: analysis involving Japanese patients from one institute. Pathol Int 2009;59:359-67.

2. Liu Z, Zhou G, Nakamura M, et al. Encapsulated follicular thyroid tumor with equivocal nuclear changes, so-called well-differentiated tumor of uncertain malignant potential: a morphological, immunohistochemical, and molecular appraisal. Cancer Sci 2011;102:288-94.

3. Kakudo K, Bai Y, Liu Z, et al. Classification of thyroid follicular cell tumors: with special reference to borderline lesions. Endocr J 2012;59:1-12.

4. Kakudo K, Bai Y, Liu Z, et al. Encapsulated papillary thyroid carcinoma, follicular variant: a misnomer. Pathol Int 2012;62:155-60.

5. Kakudo K, Wakasa T, Kakudo M, et al. Borderline and precursor lesions of thyroid neoplasms: A missing link. J Basic and Clin Med 2015;4:2-7.

6. Kakudo K, Wakasa T, Ohta Y, et al. Prognostic classification of thyroid follicular cell tumors using Ki-67 labelling index: Risk stratification of thyroid follicular cell carcinomas. Endocr J 2015;62:1-12.

7. DeLellis RA, Lloyd RV, Heitz PU, et al. Tumours of Endocrine Organs, World Health Organization Classification of Tumours;Pathology and Genetics. the 3rd Edition. Lyon: IARC Press, 2004.

8. DeLellis RA, Nunnemacher G, Wolfe HJ. C-cell hyperplasia. An ultrastructural analysis. Lab Invest 1977;36:237-48.

9. Wolfe HJ, Melvin KE, Cervi-Skinner SJ, et al. C-cell hyperplasia preceding medullary thyroid carcinoma. $\mathrm{N}$ Engl J Med 1973;289:437-41.

10. Kakudo K. Ultrastructural study of medullary carcinoma 
of the thyroid. Med J Osaka Univ 1977;27:101-15.

11. Perry A, Molberg K, Albores-Saavedra J. Physiologic versus neoplastic $\mathrm{C}$-cell hyperplasia of the thyroid: separation of distinct histologic and biologic entityes. Cancer 1996;77:750-6.

12. van Heerden JA, Hay ID, Goellner JR, et al. Follicular thyroid carcinoma with capsular invasion alone: a nonthreatening malignancy. Surgery 1992;112:1130-6; discussion 1136-8.

13. Schröder S, Böcker W, Dralle H, et al. The encapsulated papillary carcinoma of the thyroid. A morphologic subtype of papillary thyroid carcinoma. Cancer 1984;54:90-3.

14. Bai Y, Kakudo K, Li Y, et al. Subclassification of non-solid type papillary carcinoma, identification of high-risk group in common type. Cancer Sci, 2008;99:1908-15.

15. Piana S, Frasoldati A, Di Felice E, et al. Encapsulated welldifferentiated follicular-patterned thyroid carcinomas do not play a significant role in the fatality rates from thyroid carcinoma. Am J Surg Pathol 2010;34:868-72.

16. Goffredo P, Cheung K, Roman SA, et al. Can minimally invasive follicular thyroid cancer be approached as a benign lesion? A population-level analysis of survival among 1200 patients. Ann Surg Oncol 2013;20:767-72.

17. Liu J, Singh B, Tallini G, et al. Follicular variant of papillary thyroid carcinoma: A clinicopathologic study of a problematic entity. Cancer 2006;107:1255-64.

18. Vivero M, Kraft S, Barletta J. Risk stratification of follicular variant of papillary thyroid carcinoma. Thyroid 2013;23:273-9.

19. Ganly I, Wang L, Tuttle MR, et al. Invasion rather than nuclear features correlates with outcome in encapsulated follicular tumors: further evidence for the reclassification of the encapsulated papillary thyroid carcinoma follicular variant. Hum Pathol 2015;46:657-64.

20. Nikiforov YE, Seethala RR, Tallini G, et al. Nomenclature Revision for Encapsulated Follicular Variant of Papillary Thyroid Carcinoma: A Paradigm Shift to Reduce Overtreatment of Indolent Tumors. JAMA Oncol 2016;2:1023-9.

21. Leboulleux S, Tuttle RM, Paccini F, et al. Papillary thyroid microcarcinoma: time to shift from surgery to active surveillance. Lancet Diabetes Endocrinol 2016;4:933-42.

22. Harach HR, Franssila KO, Wasenius VM. Occult papillary carcinoma of the thyroid. A "normal" finding in Finland. A systematic autopsy study. Cancer 1985;56:531-8.

23. Miyauchi A. Clinical trials of active surveillance of papillary microcarcinoma of the thyroid. World J Surg 2016;40:516-22.
24. Ito Y, Uruno T, Nakano K, et al. An observation trial without surgical treatment in patients with papillary microcarcinoma of the thyroid. Thyroid 2003;13:381-7.

25. Ito $\mathrm{Y}$, Tomoda $\mathrm{C}$, Uruno $\mathrm{T}$, et al. Papillary microcarcinoma of the thyroid: how it should be treated? World J Surg 2004;28:1115-21.

26. Ito Y, Miyauchi A. A therapeutic strategy for incidentally detected papillary microcarcinoma of the thyroid. Nat Clin Pract Endocrinol Metab 2007;3:240-8.

27. Ito $Y$, Miyauchi A, Inoue H, et al. An observational trial for papillary thyroid microcarcinoma in Japanese patients. World J Surg 2010;34:28-35.

28. Sugitani I, Toda K, Yamada K, et al. Three distinctly different kinds of papillary thyroid microcarcinoma should be recognized: our treatment strategies and outcomes. World J Surg 2010;34:1222-31.

29. Oda H, Miyauchi A, Ito $\mathrm{Y}$, et al. Incidences of unfavorable events in the management of low-risk papillary microcarcinoma of the thyroid by active surveillance versus immediate surgery. Thyroid 2016;26:150-5.

30. Brito JP, Ito Y, Miyauchi A, et al. A clinical framework to facilitate risk stratification when considering an active surveillance alternative to immediate biopsy and surgery in papillary microcarcinoma. Thyroid 2016;26:144-9.

31. Welch HG, Black WC. Overdiagnosis in cancer. J Natl Cancer Inst 2010;102:605-13.

32. Esserman LJ, Thompson IM, Reid B, et al. Addressing overdiagnosis and overtreatment in cancer: a prescription for change. Lancet Oncol 2014;15:e234-42.

33. Wang TS, Goffredo P, Sosa JA, et al. Papillary thyroid microcarcinoma: an over-treated malignancy? World J Surg 2014;38:2297-303.

34. Conzo G, Avenia N, Ansaldo GL, et al. Surgical treatment of thyroid follicular neoplasms: results of a retrospective analysis of a large clinical series. Endocrine 2017;55:530-8.

35. Iyer NG, Morris LG, Tuttle RM, et al. Rising incidence of second cancers in patients with low-risk (TN) thyroid cancer who receive radioactive iodine therapy, Cancer 2011;117:4439-46.

36. Lang BH, Wong KP. Risk factors for nonsynchronous second primary malignancy and related death in patients with differentiated thyroid carcinoma, Ann Surg Oncol 2011;18:3559-65.

37. Haugen BR, Alexander EK, Bible KC, et al. 2015 American Thyroid Association Management Guidelines for Adult Patients with Thyroid Nodules and Differentiated Thyroid Cancer: The American Thyroid Association Guidelines Task Force on Thyroid Nodules and Differentiated 
Thyroid Cancer. Thyroid 2016;26:1-133.

38. Rosai J, LiVolsi VA, Sobrinho-Simoes M, et al. Renaming papillary microcarcinoma of the thyroid gland: the Porto proposal. Int J Surg Pathol 2003;11:249-51.

39. Haser GC, Tuttle RM, Su HK, et al. Active surveillance for papillary thyroid microcarcinoma: new challenges and opportunities for the health care system. Endocr Pract 2016;22:602-11.

40. Kwon H, Oh HS, Kim M, et al. Active surveillance for patients with papillary thyroid microcarcinoma: a single center's experience in Korea. J Clin Endocrinol Metab 2017;102:1917-25.

41. Jeon MJ, Kim WG, Kwon H, et al. Clinical outcomes after delayed thyroid surgery in patients with papillary thyroid microcarcinoma. Eur J Endocrinol 2017;177:25-31.

42. Nickel B, Brito JP, Barratt A, et al. Clinicians' views on management and terminology for papillary thyroid microcarcinoma: A qualitative study. Thyroid 2017;27:661-71.

43. Castro P, Rebocho AP, Soares RJ, et al. PAX8PPARgamma rearrangement is frequently detected in the follicular variant of papillary thyroid carcinoma. J Clin Endocrinol Metab 2006;91:213-20.

44. Paulson VA, Shivdasani P, Angell TE, et al. Noninvasive follicular thyroid neoplasm with papillary-like nuclear features accounts for more than half of "carcinomas" harboring RAS mutations. Thyroid 2017;27:506-11.

45. Cancer Genome Atlas Research Network. Integrated genomic characterization of papillary thyroid carcinoma. Cell 2014;159:676-90.

46. American Thyroid Association (ATA) Guidelines Taskforce on Thyroid Nodules and Differentiated Thyroid Cancer, Cooper DS, Doherty GM, et al. Revised American Thyroid Association management guidelines for patients with thyroid nodules and differentiated thyroid cancer. Thyroid 2009; 19:1167-214.

47. Gharib H, Papini E, Paschke R, et al. American Association of Clinical Endocrinologists, Associazione Medici Endocrinologi, and European Thyroid Association Medical guidelines for clinical practice for the diagnosis and management of thyroid nodules: executive summary of recommendations. Endocr Pract 2010;16:468-75.

48. Lloyd RV, Osamura RY, Klöppel G. editors. WHO Classification of Tumours of Endocrine Organs (4th edition). Lyon: IARC Press, 2017.

49. Kakudo K, Katoh R, Sakamoto A, et al. Thyroid gland: International case conference. Endocr Pathol 2002;13:131-4.
50. Hirokawa M, Carney JA, Goellner JR, et al. Observer variation of encapsulated follicular lesions of the thyroid gland. Am J Surg Pathol 2002;26:1508-14.

51. Lloyd RV, Erickson LA, Casey MB, et al. Observer variation in the diagnosis of follicular variant of papillary thyroid carcinoma. Am J Surg Pathol 2004;28:1336-40.

52. Renshaw AA, Gould EW. Why there is the tendency to "overdiagnose" the follicular variant of papillary thyroid carcinoma. Am J Clin Pathol 2002;117:19-21.

53. Widder S, Guggisberg K, Khalil M, et al. A pathologic re-review of follicular thyroid neoplasms: the impact of changing the threashold for the diagnosis of follicular variant of papillary thyroid carcinoma. Surgery 2008;144:80-5.

54. Ohori NP. FNA cytopathology and molecular test characteristics in the changing landscape of papillary thyroid carcinoma. J Basic Clin Med 2015;4:103-9.

55. Mehrzad R, Nishino M, Connolly J, et al. The relationship between the follicular variant of papillary thyroid cancer and follicular adenomas. Surgery 2016;159:1396-406.

56. Vickery AL Jr. Thyroid papillary carcinoma: pathological and philosophical controversies. Am J Surg Pathol 1983;7:797-807.

57. Chan J. Strict criteria should be applied in the diagnosis of encapsulated follicular variant of papillary thyroid carcinoma. Am J Clin Pathol 2002;117:16-8.

58. Strickland KC, Howitt BE, Marqusee E, et al. The Impact of Noninvasive Follicular Variant of Papillary Thyroid Carcinoma on Rates of Malignancy for FineNeedle Aspiration Diagnostic Categories. Thyroid 2015;25:987-92

59. Thompson LD. Ninety-four cases of encapsulated follicular variant of papillary thyroid carcinoma: A name change to non-invasive follicular thyroid neoplasm with papillary-like nuclear features would help prevent overtreatment. Mod Pathol 2016;29:698-707.

60. Faquin WC, Wong LQ, Afrogheh AH, et al. Impact of reclassifying noninvasive follicular variant of papillary thyroid carcinoma on the risk of malignancy in The Bethesda System for Reporting Thyroid Cytopathology. Cancer Cytopathol 2016;124:181-7.

61. Pusztaszeri MP, Triponez F, Meyer P, et al. Noninvasive follicular thyroid neoplasm with papillary-like nuclear features (NIFTP): Report of an institutional experience with 86 cases. J Basic Clin Med 2017;6:29-35.

62. Saglietti C, Bongiovanni M. The value of cytological examination in the diagnosis of noninvasive thyroid neoplasm with papillary-like nuclear features (NIFTP). J 
Basic Clin Med 2017;6:57-60.

63. Bychkov A, Hirokawa M, Jung CK, et al. Low rate of noninvasive follicular thyroid neoplasm with papillary-like nuclear features in Asian practice. Thyroid 2017;27:983-4.

64. Liu Z, Song Y, Han B, et al. Non-invasive follicular thyroid neoplasm with papillary-like nuclear features and the practice in Qilu Hospital of Shandong University, China. J Basic Clin Med 2017;6:22-5.

65. Jung CK, Kim C. Effect of lowering the diagnostic threshold for encapsulated follicular variant of papillary thyroid carcinoma on the prevalence of non-invasive follicular thyroid neoplasm with papillary-like nuclear features: A single-institution experience in Korea. J Basic Clin Med 2017;6:26-8.

66. Canberk S, Gunes P, Onenerk M, et al. New concept of the encapsulated follicular variant of papillary thyroid carcinoma and its impact on the Bethesda system for reporting thyroid cytopathology: A single-institute experience. Acta Cytol 2016;60:198-204.

67. Williams ED. Two proposal regarding the terminology of thyroid tumors. Int J Surg Pathol 2000;8:181-3.

68. Haugen BR, Sawka AM, Alexander EK, et al. American Thyroid Association Guidelines on the Management of Thyroid Nodules and Differentiated Thyroid Cancer Task Force Review and Recommendation on the Proposed Renaming of Encapsulated Follicular Variant Papillary Thyroid Carcinoma Without Invasion to Noninvasive Follicular Thyroid Neoplasm with Papillary-Like Nuclear Features. Thyroid 2017;27:481-3.

69. Hodak S, Tuttle RM, Maytal G, et al. Changing the cancer diagnosis: The case of follicular variant of papillary thyroid cancer-Primum non nocere and NIFTP. Thyroid 2016;26:869-71.

70. Kakudo K. Unsettled Issues in Non-Invasive encapsulated/ well-circumscribed Follicular Thyroid neoplasm with Papillary-like nuclear features (NIFTP) and precursor thyroid tumors. J Basic Clin Med 2017;6:3-7.

71. Kakudo K, Kameyama K, Miyauchi A, et al. Introducing the reporting system for thyroid fine-needle aspiration cytology according to the new guidelines of the Japan Thyroid Association. Endocr J 2014;61:539-52.

72. Stoll SJ, Pitt SC, Liu J, et al. Thyroid hormone replacement after thyroid lobectomy. Surgery 2009;146:554-8.

73. Park S, Jeon MJ, Song E, et al. Clinical features of early and late postoperative hypothyroidism after lobectomy. J Clin Endocrinol Metab 2017;102:1317-24.

74. Howitt BE, Chang S, Eszlinger M, et al. Fine-needle aspiration diagnosis of noninvasive follicular variant of papillary carcinoma. Am J Clin Pathol 2015;144:850-7.

75. Maletta F, Massa F, Torregrossa L, et al. Cytological features of "noninvasive follicular thyroid neoplasm with papillary-like nuclear features" and their correlation with tumor histology. Hum Pathol 2016;54:134-42.

76. Krane JF, Alexander EK, Cibas ES, et al. Coming to terms with NIFTP: a provisional approach for cytologists. Cancer Cytopathol 2016;124:767-72.

77. Ibrahim AA, Wu HH. Fine-needle aspiration cytology of noninvasive follicular variant of papillary thyroid carcinoma is cytolomorphologically distinct from the invasive counterpart. Am J Clin Pathol 2016;146:373-7.

78. Yang GC, Fried KO, Scognamiglio T. Sonographic and cytologic differences of NIFTP from infiltrative or invasive encapsulated follicular variant of papillary thyroid carcinoma: A review of 179 cases. Diagn Cytopathol 2017;45:533-41.

79. Strickland KC, Vivero M, Jo VY, et al. Preoperative cytologic diagnosis of Noninvasive follicular thyroid neoplasm with papillary-like nuclear features: A prospective analysis. Thyroid 2016;26:1466-71.

80. Rossi ED. NIFTP diagnosis: Roses and thorns for cytopathologists and histopathologists. J Basic Clin Med 2017;6:36-7.

81. Yang GC. Ultrasound is cytopathologist's best friend in the era of noninvasive follicular thyroid neoplasm with papillary-like nuclear features. J Basic Clin Med 2017;6:65-7.

82. Wu HH. The impact of NIFTP on FNA cytology: Can we still diagnose papillary carcinoma? J Basic Clin Med 2017;6:61-2.

83. Rosario PW. Ultrasonography and cytology as predictors of noninvasive follicular thyroid (NIFTP) neoplasm with papillary-like nuclear features: Importance of the differential diagnosis with the invasive encapsulated follicular variant of papillary thyroid cancer. (letter to editor). Clin Endocrinol (Oxf) 2017;87:635-6.

84. Ng D, Can NT, Ma ZV, et al. Cytomorphologic features of noninvasive follicular thyroid neoplasm with papillarylike nuclear features (NIFTP): A comparison with infiltrative follicular variant of papillary thyroid carcinoma. J Basic Clin Med 2017;6:51-6.

85. Rago T, Scutari M, Latrofa F, et al. The large majority of 1520 patients with indeterminate thyroid nodule at cytology have a favorable outcome, and a clinical risk score has a high negative predictive value for a more cumbersome cancer disease. J Clin Endocrinol Metab 
2014;99:3700-7.

86. Trimboli P, Bongiovanni M, Rossi F, et al. Differentiated thyroid cancer patients with a previous indeterminate (Thy 3) cytology have a better prognosis than those with suspicious or malignant FNAC reports. Endocrine 2015;49:191-5.

87. Nishigami K, Liu Z, Taniguchi E, et al. Cytological features of well-differentiated tumors of uncertain malignant potential: indeterminate cytology and WDTUMP. Endocr J 2012;59:483-7.

88. Liu X, Medici M, Kwong N, et al. Bethesda categorization of thyroid nodule cytology and prediction of thyroid cancer type and prognosis. Thyroid 2016;26:256-61.

89. Cibas ES, Ali SZ. The Bethesda System for Reporting. Thyroid Cytopathology. Thyroid 2009;19:1159-65.

90. Ohori NP, Schoedel KE. Variability in the atypia of undetermined significance/follicular lesion of undetermined significance diagnosis in the Bethesda System for Reporting Thyroid Cytopathology: sources and recommendations. Acta Cytol 2011;55:492-8.

91. Bongiovanni M, Spitale A, Faquin WC, et al. The Bethesda system for reporting thyroid cytopathology: A meta-analysis. Acta Cytologica 2012;56:333-9.

92. Kakudo K, Kameyama K, Miyauchi A. History of thyroid cytology in Japan and reporting system recommended by the Japan Thyroid Association. J Basic Clin Med 2013;2:10-5.

93. Nakamura H, Hirokawa M, Ota H, et al. Is an increase in thyroid nodule volume a risk factor for malignancy? Thyroid 2015;25:804-11.

94. Kim DS, Kim JH, Na DG, et al. Sonographic features of follicular variant papillary thyroid carcinomas in comparison with conventional papillary thyroid carcinomas. J Ultrasound Med 2009;28:1685-92.

95. Rhee SJ, Hahn SY, Ko ES, et al. Follicular variant of papillary thyroid carcinoma: distinct biologic behavior based on ultrasonographic features. Thyroid 2014;24:683-8.

96. Jang EK, Kim WG, Choi YM, et al. Association between neck ultrasonographic findings and clinico-pathological features in the follicular variant of papillary thyroid carcinoma. Clin Endocrinol (Oxf) 2015;83:968-76.

97. Hahn SY, Shin JH, Lim HK, et al. Preoperative differentiation between noninvasive follicular thyroid neoplasm with papillary-like nuclear features (NIFTP) and non-NIFTP. Clin Endocrinol (Oxf) 2017;86:444-50.

98. Rosario PW, Mourão GF, Nunes MB, et al. Noninvasive follicular thyroid neoplasm with papillary-like nuclear features (NIFTP). Endocr Relat Cancer 2016;23:893-7.

99. Kameyama K, Sasaki E, Sugino K, et al. The Japanese Thyroid Association reporting system of thyroid aspiration cytology and experience from a high-volume center, especially in indeterminate category. J Basic Clin Med 2015;4:70-4.

100.Sugino K, Kameyama K, Ito K. Characteristics and outcome of thyroid cancer patients with indeterminate cytology. J Basic Clin Med 2015;4:92-8.

101.Lobo C, McQueen A, Beale T, et al. The UK Royal College of Pathologists thyroid fine-needle aspiration diagnostic classification is a robust tool for a clinical management of abnormal thyroid nodules. Acta Cytol 2011;55:499-506.

102. Valderrabano P, McIver B. Evaluation and management of indeterminate thyroid nodules: the revolution of risk stratification beyond cytological diagnosis. Cancer Control 2017;24:1073274817729231.

103.Elwyn G, Frosh D, Thomson R, et al. Perspective: Shared decision making: A model for clinical practice. J Gen Intern Med 2012;27:1361-7.

104. Takami H, Ito Y, Okamoto T, et al. Therapeutic strategy for differentiated thyroid carcinoma in Japan based on a newly established guideline managed by Japanese Society of Thyroid Surgeons and Japanese Association of Endocrine Surgeons. World J Surg 2011;35:111-21.

105. Yoshida A, Okamoto T. Japanese management guidelines for thyroid tumors 2010. Edited by the Japanese Association of Endocrine Surgeons and the Japanese Society of Thyroid Surgery. Tokyo: Kanehara Shuppan, 2010.

106. Takami H, Ito Y, Okamoto T, et al. Revisiting the guideline issued by the Japanese Society of Thyroid Surgeons and Japan Association of Endocrine Surgeons: a gradual move towards consensus between Japanese and Western practice in the management of thyroid carcinoma. World J Surg 2014;38:2002-10.

107. Wienhold R, Scholz M, Adler JB, et al. The management of thyroid nodules - a retrospective analysis of health insurance data. Dtsch Arztebl Int 2013;110:827-34.

Cite this article as: Kakudo K. How to handle borderline/ precursor thyroid tumors in management of patients with thyroid nodules. Gland Surg 2018;7(Suppl 1):S8-S18. doi: $10.21037 /$ gs.2017.08.02 